\title{
Some new common fixed point results through generalized altering distances on partial metric spaces
}

\author{
Abd Ghafur Bin Ahmad' ${ }^{1}$ Zaid Mohammed Fadail ${ }^{1 *}$, Hemant Kumar Nashine ${ }^{2}$, Zoran Kadelburg ${ }^{3}$ and \\ Stojan Radenović ${ }^{4}$
}

*Correspondence:

zaid_fatail@yahoo.com

'School of Mathematical Sciences,

Faculty of Science and Technology, University Kebangsaan Malaysia,

43600 UKM, Bangi, Selangor Darul Ehsan, Malaysia

Full list of author information is

available at the end of the article

\begin{abstract}
We establish common fixed point results for two pairs of weakly compatible mappings on a partial metric space, satisfying a weak contractive condition involving generalized control functions. The presented theorems extend and unify various known fixed point results. Examples are given to show that our results are proper extensions of the known ones.

MSC: $47 \mathrm{H} 10 ; 54 \mathrm{H} 25 ; 54 \mathrm{H} 10$
\end{abstract}

Keywords: partial metric space; generalized altering distance; coincidence point; common fixed point; weakly compatible mappings

\section{Introduction}

In [1], Matthews introduced the notion of a partial metric space as a part of the study of denotational semantics of dataflow networks. He showed that the Banach contraction mapping theorem can be generalized to the partial metric context for applications in program verification.

Subsequently, several authors (see, e.g., Altun and Erduran [2], Oltra et al. [3], Romaguera and Schellekens [4], Romaguera and Valero [5], Rus [6], Djukić et al. [7], Nashine et al. [8], Di Bari and Vetro [9], Paesano and Vetro [10], Shatanawi et al. [11], Shatanawi and Nashine [12], Aydi et al. [13]) derived fixed point theorems in partial metric spaces.

Altering distance functions (also called control functions) were introduced by Khan et al. [14]. Subsequently, they were used by many authors to obtain fixed point results, including those in partial metric spaces (e.g., Abdeljawad [15], Abdeljawad et al. [16, 17], Altun et al. [18], Ćirić et al. [19], Karapinar and Yüksel [20]). Generalized altering distance functions with several variables were used on metric spaces by Berinde [21], Choudhury [22] and Rao et al. [23].

In this paper, an attempt has been made to derive some common fixed point theorems for two pairs of weakly compatible mappings on partial metric spaces, satisfying a weak contractive condition involving generalized control functions. The presented theorems extend and unify various known fixed point results. Examples are given to show that our results are proper extensions of the known ones.

C) 2012 Ahmad et al: licensee Springer. This is an Open Access article distributed under the terms of the Creative Commons Attribution License (http://creativecommons.org/licenses/by/2.0), which permits unrestricted use, distribution, and reproduction in any medium, provided the original work is properly cited. 


\section{Preliminaries}

The following definitions and details about partial metrics can be seen, e.g., in $[1,24-28]$.

Definition 1 A partial metric on a nonempty set $X$ is a function $p: X \times X \rightarrow \mathbb{R}^{+}$such that for all $x, y, z \in X$ :

$\left(\mathrm{p}_{1}\right) \quad x=y \Longleftrightarrow p(x, x)=p(x, y)=p(y, y)$,

$\left(\mathrm{p}_{2}\right) \quad p(x, x) \leq p(x, y)$

( $\left.\mathrm{p}_{3}\right) p(x, y)=p(y, x)$,

$\left(\mathrm{p}_{4}\right) \quad p(x, y) \leq p(x, z)+p(z, y)-p(z, z)$.

The pair $(X, p)$ is called a partial metric space.

It is clear that, if $p(x, y)=0$, then from $\left(\mathrm{p}_{1}\right)$ and $\left(\mathrm{p}_{2}\right)$, it follows that $x=y$. But $p(x, x)$ may not be 0 .

Each partial metric $p$ on $X$ generates a $T_{0}$ topology $\tau_{p}$ on $X$ which has as a base the family of open $p$-balls $\left\{B_{p}(x, \varepsilon): x \in X, \varepsilon>0\right\}$, where $B_{p}(x, \varepsilon)=\{y \in X: p(x, y)<p(x, x)+\varepsilon\}$ for all $x \in X$ and $\varepsilon>0$. A sequence $\left\{x_{n}\right\}$ in $(X, p)$ converges to a point $x \in X$, with respect to $\tau_{p}$, if $\lim _{n \rightarrow \infty} p\left(x, x_{n}\right)=p(x, x)$. This will be denoted as $x_{n} \rightarrow x, n \rightarrow \infty$ or $\lim _{n \rightarrow \infty} x_{n}=x$. If $(X, p)$ is a partial metric space, and $T: X \rightarrow X$ is a mapping, continuous at $x_{0} \in X$ (in $\tau_{p}$ ) then, for each sequence $\left\{x_{n}\right\}$ in $X$, we have

$$
x_{n} \rightarrow x_{0} \quad \Rightarrow \quad T x_{n} \rightarrow T x_{0} .
$$

Clearly, a limit of a sequence in a partial metric space need not be unique. Moreover, the function $p(\cdot, \cdot)$ need not be continuous in the sense that $x_{n} \rightarrow x$ and $y_{n} \rightarrow y$ implies $p\left(x_{n}, y_{n}\right) \rightarrow p(x, y)$.

Definition 2 Let $(X, p)$ be a partial metric space. Then:

1 A sequence $\left\{x_{n}\right\}$ in $(X, p)$ is called a Cauchy sequence if $\lim _{n, m \rightarrow \infty} p\left(x_{n}, x_{m}\right)$ exists (and is finite).

2 The space $(X, p)$ is said to be complete if every Cauchy sequence $\left\{x_{n}\right\}$ in $X$ converges, with respect to $\tau_{p}$, to a point $x \in X$ such that $p(x, x)=\lim _{n, m \rightarrow \infty} p\left(x_{n}, x_{m}\right)$.

It is easy to see that every closed subset of a complete partial metric space is complete. If $p$ is a partial metric on $X$, then the function $p^{s}: X \times X \rightarrow \mathbb{R}^{+}$given by

$$
p^{s}(x, y)=2 p(x, y)-p(x, x)-p(y, y)
$$

is a metric on $X$. Furthermore, $\lim _{n \rightarrow \infty} p^{s}\left(x_{n}, x\right)=0$ if and only if

$$
p(x, x)=\lim _{n \rightarrow \infty} p\left(x_{n}, x\right)=\lim _{n, m \rightarrow \infty} p\left(x_{n}, x_{m}\right) .
$$

Lemma 1 Let $(X, p)$ be a partial metric space.

(a) $\left\{x_{n}\right\}$ is a Cauchy sequence in $(X, p)$ if and only if it is a Cauchy sequence in the metric $\operatorname{space}\left(X, p^{s}\right)$. 
(b) The space $(X, p)$ is complete if and only if the metric space $\left(X, p^{s}\right)$ is complete.

Definition $3([22,23])$ A function $\psi:[0,+\infty)^{n} \rightarrow[0,+\infty)$ is said to be a generalized altering distance function if:

$1 \psi$ is continuous;

$2 \psi$ is increasing in each of its variables;

$3 \psi\left(t_{1}, \ldots, t_{n}\right)=0$ if and only if $t_{1}=\cdots=t_{n}=0$.

The set of generalized altering distance functions with $n$ variables will be denoted by $\mathcal{F}_{n}$. If $\psi \in \mathcal{F}_{n}$, we will write $\Psi(t)=\psi(t, t, \ldots, t)$ (obviously, this function belongs to $\mathcal{F}_{1}$ ).

Simple examples of generalized altering distance functions with, say, four variables are:

$$
\begin{aligned}
& \psi\left(t_{1}, t_{2}, t_{3}, t_{4}\right)=k \max \left\{t_{1}, t_{2}, t_{3}, t_{4}\right\}, \quad k>0 ; \\
& \psi\left(t_{1}, t_{2}, t_{3}, t_{4}\right)=t_{1}^{p}+t_{2}^{q}+t_{3}^{r}+t_{4}^{s}, \quad p, q, r, s \geq 1 .
\end{aligned}
$$

Recall also the following notions. Let $X$ be a nonempty set and $T_{1}, T_{2}: X \rightarrow X$ be given self-maps on $X$. If $w=T_{1} x=T_{2} x$ for some $x \in X$, then $x$ is called a coincidence point of $T_{1}$ and $T_{2}$, and $w$ is called a point of coincidence of $T_{1}$ and $T_{2}$. The pair $\left\{T_{1}, T_{2}\right\}$ is said to be weakly compatible if $T_{1} T_{2} t=T_{2} T_{1} t$, whenever $T_{1} t=T_{2} t$ for some $t$ in $X$.

\section{Results}

\subsection{Some auxiliary results}

Assertions similar to the following lemma (see, e.g., [29]) were used (and proved) in the course of proofs of several fixed point results in various papers.

Lemma 2 Let $(X, d)$ be a metric space and let $\left\{y_{n}\right\}$ be a sequence in $X$ such that $\left\{d\left(y_{n+1}, y_{n}\right)\right\}$ is nonincreasing and

$$
\lim _{n \rightarrow \infty} d\left(y_{n+1}, y_{n}\right)=0
$$

If $\left\{y_{2 n}\right\}$ is not a Cauchy sequence, then there exist $\varepsilon>0$ and two sequences $\{m(k)\}$ and $\{n(k)\}$ of positive integers such that $n(k)>m(k)>k$ and the following four sequences tend to $\varepsilon$ when $k \rightarrow \infty$ :

$$
d\left(y_{2 m(k)}, y_{2 n(k)}\right), \quad d\left(y_{2 m(k)}, y_{2 n(k)+1}\right), \quad d\left(y_{2 m(k)-1}, y_{2 n(k)}\right), \quad d\left(y_{2 m(k)-1}, y_{2 n(k)+1}\right) .
$$

As a corollary (putting $d=p^{s}$ for a partial metric $p$ ), we obtain

Lemma 3 Let $(X, p)$ be a partial metric space and let $\left\{y_{n}\right\}$ be a sequence in $X$ such that $\left\{p\left(y_{n+1}, y_{n}\right)\right\}$ is nonincreasing and

$$
\lim _{n \rightarrow \infty} p\left(y_{n+1}, y_{n}\right)=0
$$

If $\left\{y_{2 n}\right\}$ is not a Cauchy sequence in $(X, p)$, then there exist $\varepsilon>0$ and two sequences $\left\{m_{k}\right\}$ and $\{n(k)\}$ of positive integers such that $n(k)>m(k)>k$ and the following four sequences 
tend to $\varepsilon$ when $k \rightarrow \infty$ :

$$
\begin{array}{ll}
p\left(y_{2 m(k)}, y_{2 n(k)}\right), & p\left(y_{2 m(k)}, y_{2 n(k)+1}\right), \\
p\left(y_{2 m(k)-1}, y_{2 n(k)}\right), & p\left(y_{2 m(k)-1}, y_{2 n(k)+1}\right) .
\end{array}
$$

\subsection{Main results}

Theorem 1 Let $(X, p)$ be a complete partial metric space. Let $T, S, I, J: X \rightarrow X$ be given mappings satisfying for every pair $(x, y) \in X \times X$ :

$$
\begin{aligned}
\Psi_{1}(p(S x, T y)) \leq & \psi_{1}\left(p(I x, J y), p(I x, S x), p(J y, T y), \frac{1}{2}[p(I x, T y)+p(J y, S x)]\right) \\
& -\psi_{2}(p(I x, J y), p(I x, S x), p(J y, T y)),
\end{aligned}
$$

where $\psi_{1} \in \mathcal{F}_{4}$ and $\psi_{2} \in \mathcal{F}_{3}$ are generalized altering distance functions, and $\Psi_{1}(t)=$ $\psi_{1}(t, t, t, t)$. Suppose that

(i) $T X \subseteq I X$ and $S X \subseteq J X$;

(ii) one of the ranges $I X, J X, T X$ and $S X$ is a closed subset of $(X, p)$.

Then

(a) I and S have a coincidence point,

(b) J and T have a coincidence point.

Moreover, if the pairs $\{I, S\}$ and $\{J, T\}$ are weakly compatible, then $I, J, T$ and $S$ have a unique common fixed point.

Proof Let $x_{0}$ be an arbitrary point in $X$. Since $T X \subseteq I X$ and $S X \subseteq J X$, we can define sequences $\left\{x_{n}\right\}$ and $\left\{y_{n}\right\}$ in $X$ by

$$
y_{2 n-1}=S x_{2 n-2}=J x_{2 n-1}, \quad y_{2 n}=T x_{2 n-1}=I x_{2 n}, \quad \forall n \in \mathbb{N} .
$$

Without loss of the generality, we may assume that

$$
p\left(y_{2 n}, y_{2 n+1}\right)>0, \quad \forall n \in \mathbb{N} .
$$

If not, then $p\left(y_{2 n}, y_{2 n+1}\right)=0$ and hence $y_{2 n}=y_{2 n+1}$, for some $n$. Taking $x=x_{2 n}$ and $y=x_{2 n+1}$, from (3.4) and the considered contraction condition (3.3), we have

$$
\begin{aligned}
\Psi_{1}\left(p\left(y_{2 n+1}, y_{2 n+2}\right)\right)= & \Psi_{1}\left(p\left(S x_{2 n}, T x_{2 n+1}\right)\right) \\
\leq & \psi_{1}\left(p\left(I x_{2 n}, J x_{2 n+1}\right), p\left(I x_{2 n}, S x_{2 n}\right), p\left(J x_{2 n+1}, T x_{2 n+1}\right),\right. \\
& \left.\frac{1}{2}\left[p\left(I x_{2 n}, T x_{2 n+1}\right)+p\left(J x_{2 n+1}, S x_{2 n}\right)\right]\right) \\
& -\psi_{2}\left(p\left(I x_{2 n}, J x_{2 n+1}\right), p\left(I x_{2 n}, S x_{2 n}\right), p\left(J x_{2 n+1}, T x_{2 n+1}\right)\right) \\
= & \psi_{1}\left(p\left(y_{2 n}, y_{2 n+1}\right), p\left(y_{2 n}, y_{2 n+1}\right), p\left(y_{2 n+1}, y_{2 n+2}\right),\right. \\
& \left.\frac{1}{2}\left[p\left(y_{2 n}, y_{2 n+2}\right)+p\left(y_{2 n+1}, y_{2 n+1}\right)\right]\right)
\end{aligned}
$$




$$
\begin{aligned}
& -\psi_{2}\left(p\left(y_{2 n}, y_{2 n+1}\right), p\left(y_{2 n}, y_{2 n+1}\right), p\left(y_{2 n+1}, y_{2 n+2}\right)\right) \\
\leq & \psi_{1}\left(p\left(y_{2 n}, y_{2 n+1}\right), p\left(y_{2 n}, y_{2 n+1}\right), p\left(y_{2 n+1}, y_{2 n+2}\right),\right. \\
& \left.\frac{1}{2}\left[p\left(y_{2 n}, y_{2 n+1}\right)+p\left(y_{2 n+1}, y_{2 n+2}\right)\right]\right) \\
& -\psi_{2}\left(p\left(y_{2 n}, y_{2 n+1}\right), p\left(y_{2 n}, y_{2 n+1}\right), p\left(y_{2 n+1}, y_{2 n+2}\right)\right),
\end{aligned}
$$

since

$$
p\left(y_{2 n}, y_{2 n+2}\right)+p\left(y_{2 n+1}, y_{2 n+1}\right) \leq p\left(y_{2 n}, y_{2 n+1}\right)+p\left(y_{2 n+1}, y_{2 n+2}\right)
$$

Suppose that $p\left(y_{2 n+1}, y_{2 n+2}\right)>0$. Using (3.6) together with $p\left(y_{2 n}, y_{2 n+1}\right)=0$ and the properties of the generalized altering distance functions $\psi_{1}, \psi_{2}$, we get

$$
\begin{aligned}
\Psi_{1}\left(p\left(y_{2 n+1}, y_{2 n+2}\right)\right) \leq & \psi_{1}\left(0,0, p\left(y_{2 n+1}, y_{2 n+2}\right), \frac{1}{2} p\left(y_{2 n+1}, y_{2 n+2}\right)\right) \\
& -\psi_{2}\left(0,0, p\left(y_{2 n+1}, y_{2 n+2}\right)\right) \\
< & \psi_{1}\left(0,0, p\left(y_{2 n+1}, y_{2 n+2}\right), \frac{1}{2} p\left(y_{2 n+1}, y_{2 n+2}\right)\right) \\
\leq & \Psi_{1}\left(p\left(y_{2 n+1}, y_{2 n+2}\right)\right),
\end{aligned}
$$

which is a contradiction. It follows that $p\left(y_{2 n+1}, y_{2 n+2}\right)=0$ and hence $y_{2 n+1}=y_{2 n+2}$. Following similar arguments, we obtain $y_{2 n+2}=y_{2 n+3}$. Thus $\left\{y_{n}\right\}$ becomes an eventually constant sequence and $y_{2 n}$ is a point of coincidence of $I$ and $S$, while $y_{2 n+1}$ is a point of coincidence of $J$ and $T$.

Assume further that (3.5) holds. We claim that

$$
\lim _{n \rightarrow \infty} p\left(y_{n+1}, y_{n+2}\right)=0
$$

Suppose that, for some $n \in \mathbb{N}$,

$$
p\left(y_{2 n+1}, y_{2 n+2}\right)>p\left(y_{2 n}, y_{2 n+1}\right) \text {. }
$$

Using this together with the properties of generalized altering distance functions $\psi_{1}, \psi_{2}$, we get from (3.6) that

$$
\begin{aligned}
\Psi_{1}( & \left.p\left(y_{2 n+1}, y_{2 n+2}\right)\right) \\
\leq & \psi_{1}\left(p\left(y_{2 n}, y_{2 n+1}\right), p\left(y_{2 n}, y_{2 n+1}\right), p\left(y_{2 n+1}, y_{2 n+2}\right), p\left(y_{2 n+1}, y_{2 n+2}\right)\right) \\
\quad & -\psi_{2}\left(p\left(y_{2 n}, y_{2 n+1}\right), p\left(y_{2 n}, y_{2 n+1}\right), p\left(y_{2 n+1}, y_{2 n+2}\right)\right) \\
\leq & \Psi_{1}\left(p\left(y_{2 n+1}, y_{2 n+2}\right)\right)-\psi_{2}\left(p\left(y_{2 n}, y_{2 n+1}\right), p\left(y_{2 n}, y_{2 n+1}\right), p\left(y_{2 n+1}, y_{2 n+2}\right)\right) .
\end{aligned}
$$

This implies that

$$
\psi_{2}\left(p\left(y_{2 n}, y_{2 n+1}\right), p\left(y_{2 n}, y_{2 n+1}\right), p\left(y_{2 n+1}, y_{2 n+2}\right)\right)=0
$$


which yields that $p\left(y_{2 n+1}, y_{2 n}\right)=0$. Hence, we obtain a contradiction with (3.5). We deduce that

$$
p\left(y_{2 n+1}, y_{2 n+2}\right) \leq p\left(y_{2 n}, y_{2 n+1}\right), \quad \forall n \in \mathbb{N}
$$

By a similar reasoning, we obtain that

$$
p\left(y_{2 n+2}, y_{2 n+3}\right) \leq p\left(y_{2 n+1}, y_{2 n+2}\right), \quad \forall n \in \mathbb{N}
$$

Combining (3.8) and (3.9), we obtain

$$
p\left(y_{n+1}, y_{n+2}\right) \geq p\left(y_{n+2}, y_{n+3}\right), \quad \forall n \in \mathbb{N} \text {. }
$$

Then, $\left\{p\left(y_{n+1}, y_{n+2}\right)\right\}$ is a nonincreasing sequence of positive real numbers. This implies that there exists $r \geq 0$ such that

$$
\lim _{n \rightarrow \infty} p\left(y_{n+1}, y_{n+2}\right)=r
$$

By (3.6), we have

$$
\begin{aligned}
\Psi_{1}( & \left.p\left(y_{2 n+1}, y_{2 n+2}\right)\right) \\
\leq & \psi_{1}\left(p\left(y_{2 n}, y_{2 n+1}\right), p\left(y_{2 n}, y_{2 n+1}\right), p\left(y_{2 n}, y_{2 n+1}\right), p\left(y_{2 n}, y_{2 n+1}\right)\right) \\
& \quad-\psi_{2}\left(p\left(y_{2 n}, y_{2 n+1}\right), p\left(y_{2 n}, y_{2 n+1}\right), p\left(y_{2 n+1}, y_{2 n+2}\right)\right), \\
= & \Psi_{1}\left(p\left(y_{2 n}, y_{2 n+1}\right)\right)-\psi_{2}\left(p\left(y_{2 n}, y_{2 n+1}\right), p\left(y_{2 n}, y_{2 n+1}\right), p\left(y_{2 n+1}, y_{2 n+2}\right)\right) .
\end{aligned}
$$

Letting $n \rightarrow \infty$ in (3.11) and using continuity of $\Psi_{1}$ and $\psi_{2}$, we obtain

$$
\Psi_{1}(r) \leq \Psi_{1}(r)-\psi_{2}(r, r, r)
$$

which implies that $\psi_{2}(r, r, r)=0$, and thus $r=0$. Hence, (3.7) is proved.

Next, we claim that $\left\{y_{n}\right\}$ is a Cauchy sequence in the space $(X, p)$ (and also in the metric space $\left(X, p^{s}\right)$ by Lemma 1$)$. For this it is sufficient to show that $\left\{y_{2 n}\right\}$ is a Cauchy sequence. Suppose that this is not the case. Then, using Lemma 3 we get that there exist $\varepsilon>0$ and two sequences $\{m(i)\}$ and $\{n(i)\}$ of positive integers such that $n(i)>m(i)>i$ and sequences (3.2) tend to $\varepsilon$ when $i \rightarrow \infty$. Applying condition (3.3) to elements $x=x_{2 m(i)}$ and $y=x_{2 n(i)-1}$, we get that

$$
\begin{aligned}
\Psi_{1}\left(p\left(y_{2 m(i)+1}, y_{2 n(i)}\right)\right)= & \Psi_{1}\left(p\left(S x_{2 m(i)}, T x_{2 n(i)-1}\right)\right) \\
\leq & \psi_{1}\left(p\left(y_{2 m(i)}, y_{2 n(i)-1}\right), p\left(y_{2 m(i)}, y_{2 m(i)+1}\right), p\left(y_{2 n(i)-1}, y_{2 n(i)}\right),\right. \\
& \left.\frac{1}{2}\left[p\left(y_{2 m(i)}, y_{2 n(i)}\right)+p\left(y_{2 n(i)-1}, y_{2 m(i)+1}\right)\right]\right) \\
& -\psi_{2}\left(p\left(y_{2 m(i)}, y_{2 n(i)-1}\right), p\left(y_{2 m(i)}, y_{2 m(i)+1}\right), p\left(y_{2 n(i)-1}, y_{2 n(i)}\right)\right) .
\end{aligned}
$$


Passing to the limit as $i \rightarrow \infty$ in the last inequality (and using the continuity of the functions $\psi_{1}, \psi_{2}$ ), we obtain

$$
\Psi_{1}(\varepsilon) \leq \psi_{1}(\varepsilon, 0,0, \epsilon)-\psi_{2}(\varepsilon, 0,0) \leq \Psi_{1}(\varepsilon)-\psi_{2}(\varepsilon, 0,0)
$$

which implies that $\psi_{2}(\varepsilon, 0,0)=0$, that is a contradiction since $\varepsilon>0$. We deduce that $\left\{y_{n}\right\}$ is a Cauchy sequence.

Finally, we prove the existence of a common fixed point of the four mappings $I, J, S$ and $T$.

Since $(X, p)$ is complete, then from Lemma $1,\left(X, p^{s}\right)$ is a complete metric space. Therefore, the sequence $\left\{y_{n}\right\} p^{s}$-converges to some $z \in X$ that is, $\lim _{n \rightarrow \infty} p^{s}\left(y_{n}, z\right)=0$. From (2.2), we have

$$
p(z, z)=\lim _{n \rightarrow \infty} p\left(y_{n}, z\right)=\lim _{m \geq n \rightarrow \infty} p\left(y_{n}, y_{m}\right) .
$$

Moreover, since $\left\{y_{n}\right\}$ is a Cauchy sequence in the metric space $\left(X, p^{s}\right)$, then $\lim _{n, m \rightarrow \infty} p^{s}\left(y_{n}, y_{m}\right)=0$. On the other hand, by $\left(\mathrm{p}_{2}\right)$ and (3.7), we have $p\left(y_{n}, y_{n}\right) \leq$ $p\left(y_{n}, y_{n+1}\right) \rightarrow 0, n \rightarrow \infty$ and hence

$$
\lim _{n \rightarrow \infty} p\left(y_{n}, y_{n}\right)=0 .
$$

Thus from the definition of $p^{s}$ and (3.13), we have $\lim _{m \geq n \rightarrow \infty} p\left(y_{n}, y_{m}\right)=0$. Therefore, from (3.12), we have

$$
p(z, z)=\lim _{n \rightarrow \infty} p\left(y_{n}, z\right)=\lim _{m \geq n \rightarrow \infty} p\left(y_{n}, y_{m}\right)=0 .
$$

This implies that

$$
\lim _{n \rightarrow \infty} p\left(y_{2 n}, z\right)=\lim _{n \rightarrow \infty} p\left(y_{2 n+1}, z\right)=0 .
$$

Thus we have

$$
\lim _{n \rightarrow \infty} p\left(T x_{2 n-1}, z\right)=\lim _{n \rightarrow \infty} p\left(I x_{2 n}, z\right)=0
$$

and

$$
\lim _{n \rightarrow \infty} p\left(S x_{2 n}, z\right)=\lim _{n \rightarrow \infty} p\left(J x_{2 n+1}, z\right)=0 .
$$

Now we can suppose, without loss of generality, that $I X$ is a closed subset of the partial metric space $(X, p)$. From (3.15), there exists $u \in X$ such that $z=I u$. We claim that $S u=z$. Suppose, to the contrary, that $p(\mathrm{Su}, z)>0$. By $\left(\mathrm{p}_{4}\right)$ we get

$$
\begin{aligned}
p(z, S u) & \leq p\left(z, T x_{2 n-1}\right)+p\left(S u, T x_{2 n-1}\right)-p\left(T x_{2 n-1}, T x_{2 n-1}\right) \\
& \leq p\left(z, y_{2 n}\right)+p\left(S u, y_{2 n}\right) .
\end{aligned}
$$

It follows by (3.15) that

$$
p(z, S u) \leq \limsup _{n \rightarrow \infty} p\left(S u, y_{2 n}\right) .
$$


Then, since $\Psi_{1}$ is increasing and continuous, we get that

$$
\Psi_{1}(p(z, S u)) \leq \limsup _{n \rightarrow \infty} \Psi_{1}\left(p\left(S u, y_{2 n}\right)\right)
$$

Now, from (3.3)

$$
\begin{aligned}
\Psi_{1}\left(p\left(S u, y_{2 n}\right)\right)= & \Psi_{1}\left(p\left(S u, T x_{2 n-1}\right)\right) \\
\leq & \psi_{1}\left(p\left(I u, J x_{2 n-1}\right), p(I u, S u), p\left(J x_{2 n-1}, T x_{2 n-1}\right),\right. \\
& \left.\frac{1}{2}\left[p\left(I u, T x_{2 n-1}\right)+p\left(S u, J x_{2 n-1}\right)\right]\right) \\
& -\psi_{2}\left(p\left(I u, J x_{2 n-1}\right), p(I u, S u), p\left(J x_{2 n-1}, T x_{2 n-1}\right)\right) \\
\leq & \psi_{1}\left(p\left(z, y_{2 n-1}\right), p(z, S u), p\left(y_{2 n-1}, y_{2 n}\right),\right. \\
& \left.\frac{1}{2}\left[p\left(z, y_{2 n}\right)+p(S u, z)+p\left(z, y_{2 n-1}\right)-p(z, z)\right]\right) \\
& -\psi_{2}\left(p\left(z, y_{2 n-1}\right), p(z, S u), p\left(y_{2 n-1}, y_{2 n}\right)\right) .
\end{aligned}
$$

Passing to the upper limit as $n \rightarrow \infty$ in (3.17), we obtain using (3.14) and the continuity of $\psi_{1}, \psi_{2}$ that

$$
\begin{aligned}
\limsup _{n \rightarrow \infty} \Psi_{1}\left(p\left(S u, y_{2 n}\right)\right) & \leq \psi_{1}\left(0, p(z, S u), 0, \frac{1}{2} p(S u, z)\right)-\psi_{2}(0, p(z, S u), 0) \\
& <\Psi_{1}(p(z, S u)) .
\end{aligned}
$$

Therefore, from (3.16) we have

$$
\Psi_{1}(p(z, S u))<\Psi_{1}(p(z, S u))
$$

which is a contradiction. Thus we deduce that

$$
p(z, S u)=0 \text { and } \quad z=S u .
$$

We get that $S u=I u=z$, so $u$ is a coincidence point of $I$ and $S$.

From $S X \subset J X$ and (3.18), we have $z \in J X$. Hence we deduce that there exists $v \in X$ such that $z=J v$. We claim that $T v=z$. Suppose, to the contrary, that $p(T v, z)>0$. From (3.3), we have

$$
\begin{aligned}
\Psi_{1}(p(z, T v))= & \Psi_{1}(p(S u, T v)) \\
\leq & \psi_{1}\left(p(I u, J v), p(I u, S u), p(J v, T v), \frac{1}{2}[p(I u, T v)+p(S u, J v)]\right) \\
& -\psi_{2}(p(I u, J v), p(I u, S u), p(J v, T v)) \\
= & \psi_{1}\left(p(z, z), p(z, z), p(z, T v), \frac{1}{2}[p(z, T v)+p(z, z)]\right)
\end{aligned}
$$




$$
\begin{gathered}
-\psi_{2}(p(z, z), p(z, z), p(z, T v)) \\
<\psi_{1}\left(0,0, p(z, T v), \frac{1}{2} p(z, T v)\right) \leq \Psi_{1}(p(z, T v)),
\end{gathered}
$$

which is a contradiction. Then, we deduce that

$$
p(z, T v)=0 \quad \text { and } \quad z=T v .
$$

We get that $J v=T v=z$, so $v$ is a coincidence point of $J$ and $S$.

Since the pair $\{S, I\}$ is weakly compatible, from (3.18), we have $S z=S I u=I S u=I z$. We claim that $S z=z$. Suppose, to the contrary, that $p(S z, z)>0$. Then we have

$$
p(S z, z) \leq p\left(S z, y_{2 n}\right)+p\left(y_{2 n}, z\right)=p\left(S z, T x_{2 n-1}\right)+p\left(y_{2 n}, z\right) .
$$

Again from (3.15) we get that

$$
p(S z, z) \leq \limsup _{n \rightarrow \infty} p\left(S z, T x_{2 n-1}\right)
$$

Then, since $\Psi_{1}$ is increasing and continuous, we get

$$
\Psi_{1}(p(S z, z)) \leq \limsup _{n \rightarrow \infty} \Psi_{1}\left(p\left(S z, T x_{2 n-1}\right)\right)
$$

Now, from (3.3)

$$
\begin{aligned}
\Psi_{1}\left(p\left(S z, T x_{2 n-1}\right)\right) \leq & \psi_{1}\left(p\left(I z, J x_{2 n-1}\right), p(I z, S z), p\left(J x_{2 n-1}, T x_{2 n-1}\right),\right. \\
& \left.\frac{1}{2}\left[p\left(I z, T x_{2 n-1}\right)+p\left(S z, J x_{2 n-1}\right)\right]\right) \\
& -\psi_{2}\left(p\left(I z, J x_{2 n-1}\right), p(I z, S z), p\left(J x_{2 n-1}, T x_{2 n-1}\right)\right) \\
\leq & \psi_{1}\left(\left[p(S z, z)+p\left(z, y_{2 n-1}\right)-p(z, z)\right], p(S z, S z), p\left(y_{2 n-1}, y_{2 n}\right),\right. \\
& \left.\frac{1}{2}\left[p\left(S z, y_{2 n}\right)+p(S z, z)+p\left(z, y_{2 n-1}\right)-p(z, z)\right]\right) \\
& -\psi_{2}\left(p\left(S z, y_{2 n-1}\right), p(S z, S z), p\left(y_{2 n-1}, y_{2 n}\right)\right) .
\end{aligned}
$$

Passing to the upper limit as $n \rightarrow \infty$, we obtain ( $\operatorname{since} p(S z, S z) \leq p(S z, z))$

$$
\begin{aligned}
\limsup _{n \rightarrow \infty} \Psi_{1}\left(p\left(S z, T x_{2 n-1}\right)\right) \leq & \psi_{1}(p(S z, z), p(S z, S z), 0, p(S z, z)) \\
& -\psi_{2}(p(S z, z), p(S z, S z), 0) \\
& <\Psi_{1}(p(S z, z)) .
\end{aligned}
$$

Therefore, from (3.20) we have

$$
\Psi_{1}(p(S z, z))<\Psi_{1}(p(S z, z))
$$


a contradiction. This implies that

$$
p(S z, z)=0 \quad \text { and } \quad z=S z .
$$

Hence, we have

$$
S z=z=I z \text {. }
$$

Since the pair $\{T, J\}$ is weakly compatible, from (3.19), we have $T z=T J v=J T v=J z$. We claim that $T z=z$. Suppose, to the contrary, that $p(T z, z)>0$, then by (3.3), we have

$$
\begin{aligned}
\Psi_{1}(p(z, T z))= & \Psi_{1}(p(S z, T z)) \\
\leq & \psi_{1}\left(p(I z, J z), p(I z, S z), p(J z, T z), \frac{1}{2}[p(I z, T z)+p(S z, J z)]\right) \\
& -\psi_{2}(p(I z, J z), p(I z, S z), p(J z, T z)) \\
= & \psi_{1}\left(p(z, T z), 0, p(T z, T z), \frac{1}{2}[p(z, T z)+p(z, T z)]\right) \\
& -\psi_{2}(p(z, T z), 0, p(T z, T z)) \\
\leq & \Psi_{1}(p(z, T z))-\psi_{2}(p(z, T z), 0, p(T z, T z)) .
\end{aligned}
$$

Therefore, $\psi_{2}(p(T z, z), 0, p(T z, T z))=0$. Hence, we have $p(z, T z)=0$ and

$$
T z=z=J z .
$$

Now, combining (3.21) and (3.22), we deduce

$$
z=I z=S z=T z=J z,
$$

so $z$ is a common fixed point of the four mappings $I, J, S$ and $T$.

We claim that there is a unique common fixed point of $S, T, I$ and $J$. Assume on contrary that, $S u=T u=I u=J u=u$ and $S v=T v=I v=J v=v$ with $p(u, v)>0$. By supposition, we can replace $x$ by $u$ and $y$ by $v$ in (3.3) to obtain

$$
\begin{aligned}
\Psi_{1}(p(u, v))= & \Psi_{1}(p(S u, T v)) \\
\leq & \psi_{1}\left(p(I u, J v), p(I u, S u), p(J v, T v), \frac{1}{2}[p(I u, T v)+p(S u, J v)]\right) \\
& -\psi_{2}(p(I u, J v), p(I u, S u), p(J v, T v)) \\
= & \psi_{1}(p(u, v), 0,0, p(u, v))-\psi_{2}(p(u, v), 0,0) \\
< & \Psi_{1}(p(u, v)),
\end{aligned}
$$

a contradiction. Hence $p(u, v)=0$, that is, $u=v$. We conclude that $S, T, I$ and $J$ have only one common fixed point in $X$. The proof is complete.

It is easy to state the corollary of Theorem 1 involving a contraction of integral type. 
Corollary 1 Let T, S, I and J as well as $\psi_{1}, \psi_{2}$ satisfy the conditions of Theorem 1, except that condition (3.3) is replaced by the following: there exists a positive Lebesgue integrable function $u$ on $\mathbb{R}^{+}$such that $\int_{0}^{\varepsilon} u(t) d t>0$ for each $\varepsilon>0$ and that

$$
\begin{aligned}
\int_{0}^{\Psi_{1}(p(S x, T y))} u(t) d t \leq & \int_{0}^{\psi_{1}\left(p(I x, J y), p(I x, S x), p(y y, T y), \frac{1}{2}[p(I I x, T y)+p(J y, S x)]\right)} u(t) d t \\
& -\int_{0}^{\psi_{2}((p(I x, J y), p(I x, S x), p(y, T y))} u(t) d t,
\end{aligned}
$$

for all $x, y \in X$. Then, $S, T, I$ and $J$ have a unique common fixed point.

If in Theorem $1 I=J$ is the identity mapping on $X$, then we have the following consequence:

Theorem 2 Let $(X, p)$ be a complete partial metric space. Let $T, S: X \rightarrow X$ be given mappings satisfying for every pair $(x, y) \in X \times X$

$$
\begin{aligned}
\Psi_{1}(p(S x, T y)) \leq & \psi_{1}\left(p(x, y), p(x, S x), p(y, T y), \frac{1}{2}[p(x, T y)+p(y, S x)]\right) \\
& -\psi_{2}(p(x, y), p(x, S x), p(y, T y)),
\end{aligned}
$$

where $\psi_{1} \in \mathcal{F}_{4}$ and $\psi_{2} \in \mathcal{F}_{3}$ are altering distance functions, and $\Psi_{1}(t)=\psi_{1}(t, t, t, t)$. Then $T$ and $S$ have a unique common fixed point.

Remark 1 Several corollaries of Theorems 1 and 2 could be derived for particular choices of $\psi_{1}$ and $\psi_{2}$. We state some of them.

Putting $\psi_{1}\left(t_{1}, t_{2}, t_{3}, t_{4}\right)=\psi\left(\max \left\{t_{1}, t_{2}, t_{3}, t_{4}\right\}\right)$ and $\psi_{2}\left(t_{1}, t_{2}, t_{3}\right)=\phi\left(\max \left\{t_{1}, t_{2}, t_{3}\right\}\right)$ for $\psi, \phi \in \mathcal{F}_{1},[15$, Theorem 9] is obtained.

It is clear from the proof of Theorem 1 that condition (3.3), resp. (3.23), can be replaced by

$$
\begin{aligned}
\Psi_{1}(p(S x, T y)) & \\
\leq & \psi_{1}\left(p(I x, J y), p(I x, S x), p(J y, T y), \frac{1}{2}[p(I x, T y)+p(J y, S x)]\right) \\
& -\psi_{2}\left(p(I x, J y), p(I x, S x), p(J y, T y), \frac{1}{2}[p(I x, T y)+p(J y, S x)]\right),
\end{aligned}
$$

resp.

$$
\begin{aligned}
& \Psi_{1}(p(S x, T y)) \\
& \quad \leq \psi_{1}\left(p(x, y), p(x, S x), p(y, T y), \frac{1}{2}[p(x, T y)+p(y, S x)]\right) \\
& \quad-\psi_{2}\left(p(x, y), p(x, S x), p(y, T y), \frac{1}{2}[p(x, T y)+p(y, S x)]\right),
\end{aligned}
$$

where $\psi_{2} \in \mathcal{F}_{4}$. Hence, Theorem 1 can be considered an extension of [23, Theorem 2.1] to the frame of partial metric spaces (since semi-compatible mappings are weakly compatible). 
Putting $\psi_{1}\left(t_{1}, t_{2}, t_{3}, t_{4}\right)=\max \left\{t_{1}, t_{2}, t_{3}, t_{4}\right\}$ and $\psi_{2}=(1-r) \psi_{1}$, with $0 \leq r<1$, in Theorem 2 (with condition (3.25)), we obtain [20, Theorem 8]. The same substitution in Theorem 1 (with (3.24)) gives an improvement of [20, Theorem 12] (since only weak compatibility and not commutativity of the respective mappings is assumed).

Putting $\psi_{1}\left(t_{1}, t_{2}, t_{3}, t_{4}\right)=\max \left\{t_{1}, t_{2}, t_{3}, t_{4}\right\}$ and $\psi_{2}=\varphi \circ \psi_{1}$ for $\varphi \in \mathcal{F}_{1}$ in Theorem 2 (with condition (3.25)), [16, Theorem 5] is obtained.

Of course, several known results from the frame of standard metric spaces (see, e.g., [30] and [31]) are also special cases of these theorems. For example, the following corollary can be obtained as a consequence of Theorem 2, which is a generalization and extension of [31, Corollary 3.2].

Corollary 2 Let $(X, p)$ be a complete partial metric space. Let $T, S: X \rightarrow X$ be given mappings satisfying for every pair $(x, y) \in X \times X$

$$
\begin{aligned}
& \Psi_{1}\left(p\left(S^{m} x, T^{n} y\right)\right) \\
& \leq \psi_{1}\left(p(x, y), p\left(x, S^{m} x\right), p\left(y, T^{n} y\right), \frac{1}{2}\left[p\left(x, T^{n} y\right)+p\left(y, S^{m} x\right)\right]\right) \\
& \quad-\psi_{2}\left(p(x, y), p\left(x, S^{m} x\right), p\left(y, T^{n} y\right)\right),
\end{aligned}
$$

where $m$ and $n$ are positive integers, $\psi_{1} \in \mathcal{F}_{4}$ and $\psi_{2} \in \mathcal{F}_{3}$ are altering distance functions, and $\Psi_{1}(t)=\psi_{1}(t, t, t, t)$. Then $T$ and $S$ have a unique common fixed point.

Remark 2 However, it is not possible to use $\psi_{1}, \psi_{2} \in \mathcal{F}_{5}$ in Theorems 1 and 2, as the following example, adapted from [23, Example 2.3], shows.

Example 1 Let $X=\{1,2,3,4\}$ and $p: X \times X \rightarrow X$ be given by $p(x, x)=\frac{1}{2}$ for $x \in X, p(1,2)=$ $p(3,4)=2, p(1,3)=p(2,4)=1, p(1,4)=p(2,3)=\frac{3}{2}$ and $p(y, x)=p(x, y)$ for $x, y \in X$. Then $(X, p)$ is a (complete) partial metric space. Consider the mappings $S, T: X \rightarrow X$ defined by

$$
S=\left(\begin{array}{llll}
1 & 2 & 3 & 4 \\
2 & 1 & 1 & 2
\end{array}\right), \quad T=\left(\begin{array}{llll}
1 & 2 & 3 & 4 \\
4 & 3 & 4 & 3
\end{array}\right)
$$

and the functions $\psi_{1}, \psi_{2} \in \mathcal{F}_{5}$ given as $\psi_{1}\left(t_{1}, t_{2}, t_{3}, t_{4}, t_{5}\right)=\max \left\{t_{1}, t_{2}, t_{3}, t_{4}, t_{5}\right\}$ and $\psi_{2}=$ $\frac{1}{4} \psi_{1}$. It is easy to check that

$$
\begin{aligned}
p(S x, T y) & \leq \frac{3}{4} \max \{p(x, y), p(x, S x), p(y, T y), p(x, T y), p(y, S x)\} \\
& =\psi_{1}(\cdots)-\psi_{2}(\cdots)
\end{aligned}
$$

holds for all $x, y \in X$. However, these mappings have no common fixed points; hence, condition (3.23) (or (3.25)) of Theorem 2 cannot be replaced by the respective condition with 5 variables. At the same time, condition (3.25) is not satisfied since, for $x=3, y=1$, $p(S x, T y)=p(1,4)=\frac{3}{2}$ and

$$
\max \left\{p(x, y), p(x, S x), p(y, T y), \frac{1}{2}[p(x, T y)+p(y, S x)]\right\}=\max \left\{1,1, \frac{3}{2}, \frac{1}{2}\left(2+\frac{1}{2}\right)\right\}=\frac{3}{2}
$$


hence,

$$
\Psi_{1}(p(S x, T y))=\frac{3}{2}>\psi_{1}(\cdots)-\psi_{2}(\cdots)
$$

whatever $\psi_{2} \in \mathcal{F}_{4}$ is chosen.

This example also shows (as in [23, Remark 2.4]) the importance of the second generalized altering distance function $\psi_{2}$ in Theorems 1 and 2 .

The next example shows that Theorems 1 and 2 are proper extensions of the respective results in standard metric spaces.

Example 2 Let $X=[0,1]$ be endowed with the partial metric $p(x, y)=\max \{x, y\}$. Consider the mappings $S, T: X \rightarrow X$ defined by

$$
S x=T x=\frac{x^{2}}{1+x}
$$

and the functions $\psi_{1}, \psi_{2} \in \mathcal{F}_{4}$, given by

$$
\psi_{1}\left(t_{1}, t_{2}, t_{3}, t_{4}\right)=\max \left\{t_{1}, t_{2}, t_{3}, t_{4}\right\}, \quad \psi_{2}\left(t_{1}, t_{2}, t_{3}, t_{4}\right)=\frac{\max \left\{t_{1}, t_{2}, t_{3}, t_{4}\right\}}{1+\max \left\{t_{1}, t_{2}, t_{3}, t_{4}\right\}} .
$$

Take arbitrary elements, say $y \leq x$, from $X$. Then

$$
p(S x, T y)=\max \left\{\frac{x^{2}}{1+x}, \frac{y^{2}}{1+y}\right\}=\frac{x^{2}}{1+x}, \quad \text { and } \quad \Psi_{1}(p(S x, T y))=\frac{x^{2}}{1+x} .
$$

On the other hand,

$$
\begin{aligned}
& \max \left(p(x, y), p(x, S x), p(y, T y), \frac{1}{2}[p(x, T y)+p(y, S x)]\right) \\
& =\max \left\{p(x, y), p\left(x, \frac{x^{2}}{1+x}\right), p\left(y, \frac{y^{2}}{1+y}\right), \frac{1}{2}\left(p\left(x, \frac{y^{2}}{1+y}\right)+p\left(y, \frac{x^{2}}{1+x}\right)\right)\right\} \\
& =\max \left\{x, x, y, \frac{1}{2}\left(x+\max \left\{y, \frac{x^{2}}{1+x}\right\}\right)\right\}=x,
\end{aligned}
$$

and

$$
\begin{aligned}
\psi_{1}\left(p(x, y), p(x, S x), p(y, T y), \frac{1}{2}[p(x, T y)+p(y, S x)]\right) \\
\quad-\psi_{2}\left(p(x, y), p(x, S x), p(y, T y), \frac{1}{2}[p(x, T y)+p(y, S x)]\right) \\
=x-\frac{x}{1+x}=\frac{x^{2}}{1+x} .
\end{aligned}
$$

Hence, condition (3.25) is satisfied, as well as other conditions of Theorem 2. Mappings $S, T$ have a common fixed point $z=0$. 
On the other hand, consider the same problem in the standard metric $d(x, y)=p^{s}(x, y)=$ $|x-y|$ and take $x=1$ and $y=\frac{1}{2}$. Then

$$
d(S x, T y)=\left|\frac{1}{2}-\frac{1}{6}\right|=\frac{1}{3}
$$

and

$$
\begin{aligned}
& \max \left(d(x, y), d(x, S x), d(y, T y), \frac{1}{2}[d(x, T y)+d(y, S x)]\right) \\
& =\max \left\{\frac{1}{2}, \frac{1}{2}, \frac{1}{3}, \frac{1}{2}\left(\frac{5}{6}+0\right)\right\}=\frac{1}{2}
\end{aligned}
$$

and hence

$$
\begin{aligned}
& \psi_{1}\left(d(x, y), d(x, S x), d(y, T y), \frac{1}{2}[d(x, T y)+d(y, S x)]\right) \\
& \quad-\psi_{2}\left(d(x, y), d(x, S x), d(y, T y), \frac{1}{2}[d(x, T y)+d(y, S x)]\right) \\
& =\frac{1}{2}-\frac{\frac{1}{2}}{1+\frac{1}{2}}=\frac{1}{6} .
\end{aligned}
$$

Thus, condition (3.25) for $p=d$ does not hold and the existence of a common fixed point of these mappings cannot be derived from [23, Theorem 2.1].

\section{Competing interests}

The authors declare that they have no competing interests.

\section{Authors' contributions}

All authors contributed equally and significantly to writing this paper. All authors read and approved the final manuscript.

\section{Author details}

'School of Mathematical Sciences, Faculty of Science and Technology, University Kebangsaan Malaysia, 43600 UKM, Bangi, Selangor Darul Ehsan, Malaysia. ²Department of Mathematics, Disha Institute of Management and Technology, Satya Vihar, Vidhansabha-Chandrakhuri Marg, Mandir Hasaud, Raipur, Chhattisgarh 492101, India. ${ }^{3}$ Faculty of Mathematics, University of Belgrade, Studentski trg 16, Beograd, 11000, Serbia. ${ }^{4}$ Faculty of Mechanical Engineering, University of Belgrade, Kraljice Marije 16, Beograd, 11120, Serbia.

\section{Acknowledgements}

The first and second author would like to acknowledge the financial support received from University Kebangsaan Malaysia under the research grant OUP-UKM-FST-2012. The fourth and fifth author are thankful to the Ministry of Science and Technological Development of Serbia.

Received: 21 March 2012 Accepted: 4 July 2012 Published: 23 July 2012

\section{References}

1. Matthews, SG: Partial metric topology. In: Proc. 8th Summer Conference on General Topology and Applications. Ann. New York Acad. Sci., vol. 728, pp. 183-197 (1994)

2. Altun, I, Erduran, A: Fixed point theorems for monotone mappings on partial metric spaces. Fixed Point Theory Appl. 2011, Article ID 508730 (2011)

3. Oltra, S, Romaguera, S, Sánchez-Pérez, EA: The canonical partial metric and the uniform convexity on normed spaces. Appl. Gen. Topol. 6(2), 185-194 (2005)

4. Romaguera, S, Schellekens, M: Partial metric monoids and semivaluation spaces. Topol. Appl. 153(5-6), 948-962 (2005)

5. Romaguera, S, Valero, O: A quantitative computational model for complete partial metric spaces via formal balls. Math. Struct. Comput. Sci. 19(3), 541-563 (2009)

6. Rus, IA: Fixed point theory in partial metric spaces. An. Univ. Timiş., Ser. Mat.-Inform. (Online) 46(2), 149-160 (2008) 
7. Djukić, D, Kadelburg, Z, Radenović, S: Fixed points of Geraghty-type mappings in various generalized metric spaces. Abstr. Appl. Anal. 2011, Article ID 561245 (2011). doi:10.1155/2011/561245

8. Nashine, HK, Kadelburg, S, Radenović, S: Common fixed point theorems for weakly isotone increasing mappings in ordered partial metric spaces. Math. Comput. Model. (2011). doi:10.1016/j.mcm.2011.12.019

9. Di Bari, C, Vetro, P: Fixed points for weak $\varphi$-contractions on partial metric spaces. Int. J. Eng. Contemp. Math. Sci. 1 , 5-12 (2011)

10. Paesano, D, Vetro, P: Suzuki's type characterizations of completeness for partial metric spaces and fixed points for partially ordered metric spaces. Topol. Appl. 159, 911-920 (2012)

11. Shatanawi, W, Samet, B, Abbas, M: Coupled fixed point theorems for mixed monotone mappings in ordered partial metric spaces. Math. Comput. Model. 55, 680-687 (2012)

12. Shatanawi, W, Nashine, HK: A generalization of Banach's contraction principle for nonlinear contraction in a partial metric space. J. Nonlinear Sci. Appl. 5, 37-43 (2012)

13. Aydi, H, Karapinar, E, Shatanawi, W: Coupled fixed point results for $(\psi, \varphi)$-weakly contractive condition in ordered partial metric spaces. Comput. Math. Appl. 62, 4449-4460 (2011)

14. Khan, MS, Swaleh, M, Sessa, S: Fixed point theorems by altering distances between the points. Bull. Aust. Math. Soc. 30, 1-9 (1984)

15. Abdeljawad, T: Fixed points for generalized weakly contractive mappings in partial metric spaces. Math. Comput. Model. 54, 2923-2927 (2011)

16. Abdeljawad, T, Karapinar, E, Taş, K: Existence and uniqueness of a common fixed point on partial metric spaces. Appl. Math. Lett. 24, 1900-1904 (2011)

17. Abdeljawad, T, Karapinar, E, Taş, K: A generalized contraction principle with control functions on partial metric spaces Comput. Math. Appl. 63, 716-719 (2012)

18. Altun, I, Sola, F, Simsek, H: Generalized contractions on partial metric spaces. Topol. Appl. 157(18), 2778-2785 (2010)

19. Ćirić, LjB, Samet, B, Aydi, H, Vetro, C: Common fixed points of generalized contractions on partial metric spaces and an application. Appl. Math. Comput. 218, 2398-2406 (2011)

20. Karapinar, E, Yüksel, U: Some common fixed point theorems in partial metric spaces. J. Appl. Math. 2011, Article ID $263621(2011)$

21. Berinde, V: A common fixed point theorem for compatible quasi contractive self mappings in metric spaces. Appl. Math. Comput. 213, 348-354 (2009)

22. Choudhury, BS: A common unique fixed point result in metric spaces involving generalized altering distances. Math. Commun. 10, 105-110 (2005)

23. Rao, KPR, Ravi Babu, G, Vasu Babu, D: Common fixed point theorems through generalized altering distance functions. Math. Commun. 13, 67-73 (2008)

24. Heckmann, R: Approximation of metric spaces by partial metric spaces. Appl. Categ. Struct. 7, 71-83 (1999)

25. Oltra, S, Valero, O: Banach's fixed point theorem for partial metric spaces. Rend. Ist. Mat. Univ. Trieste 36, 17-26 (2004)

26. O'Neill, SJ: Partial metrics, valuations and domain theory. In: Proc. 11th Summer Conference on General Topology and Applications. Ann. New York Acad. Sci., vol. 806, pp. 304-315 (1996)

27. Romaguera, S: A Kirk type characterization of completeness for partial metric spaces. Fixed Point Theory Appl. 2010 Article ID 493298 (2010)

28. Valero, O: On Banach fixed point theorems for partial metric spaces. Appl. Gen. Topol. 6(2), 229-240 (2005)

29. Radenović, S, Kadelburg, Z, Jandrlić, D, Jandrlić, A: Some results on weak contraction maps. Bull. Iran. Math. Soc. (2012, to appear). Online from 30 March 2011

30. Abbas, M, Djorić, D: Common fixed point theorem for four mappings satisfying generalized weak contractive conditions. Filomat 24(2), 1-10 (2010)

31. Choudhury, BS, Konor, P, Rhoades, BE, Metiya, N: Fixed point theorems for generalized weakly contractive mappings. Nonlinear Anal. 74, 2116-2126 (2011)

doi:10.1186/1687-1812-2012-120

Cite this article as: Ahmad et al.: Some new common fixed point results through generalized altering distances on partial metric spaces. Fixed Point Theory and Applications 2012 2012:120.

\section{Submit your manuscript to a SpringerOpen ${ }^{\circ}$ journal and benefit from:}

- Convenient online submission

Rigorous peer review

- Immediate publication on acceptance

Open access: articles freely available online

- High visibility within the field

- Retaining the copyright to your article

Submit your next manuscript at $\gg$ springeropen.com 